\title{
Convergência da Produtividade Agropecuária do Sul do Brasil: uma análise espacial ${ }^{1}$
}

\author{
Augusta Pelinski Raiher ${ }^{2}$, Renato Alves de Oliveira ${ }^{3}$, \\ Alex Sander Souza do Carmo ${ }^{4}$ e Alysson Luiz Stege ${ }^{5}$
}

Resumo: Este trabalho tem como objetivo analisar a evolução da produtividade da agropecuária nas microrregiões do Sul do Brasil, identificando a existência de um processo de convergência. Para isso, mensurou-se a produtividade da agropecuária em 1995/96 e em 2006, que foi utilizada como variável dependente em um modelo de convergência. Como se confirmou a hipótese de que a distribuição espacial da produtividade da terra não é aleatória, o modelo de convergência foi estimado por meio das técnicas da econometria espacial. Os resultados obtidos confirmaram a hipótese de convergência (absoluta e condicional) da produtividade da agropecuária na região Sul do Brasil.

Palavras-chaves: Convergência; Produtividade; Região Sul.

Abstract: This work aims to analyze the evolution of land productivity in the Southern region of Brazil, identifying the existence of a convergence process. In order to do that, we measured the land productivity in 1995/96 and in 2006 and we used this variable as dependent in a convergence model. Subsequently, we estimated a convergence model using spatial econometrics. As a result, we confirmed the convergence process hypothesis (absolute and conditional) in the Southern region of Brazil.

Key-words: Convergence; Productivity; Brazilian Southern region.

DOI - http://dx.doi.org/10.1590/1234-56781806-94790540307 Classificação JEL: Q10.

1. Data de submissão: 30 de março de 2015. Data de aceite: 14 de junho de 2016.

2. Universidade Estadual de Ponta Grossa. Ponta Grossa, Paraná. E-mail: apelinski@gmail.com

3. Universidade Estadual de Ponta Grossa. Ponta Grossa, Paraná. E-mail: natoliveiralves@hotmail.com

4. Universidade Estadual de Ponta Grossa. Ponta Grossa, Paraná. E-mail: alexsscarmo@hotmail.com

5. Universidade Estadual de Ponta Grossa. Ponta Grossa, Paraná. E-mail: alyssonstege@gmail.com 


\section{Introdução}

A evidência mundial é a de que a participação da agropecuária no dinamismo econômico apresenta tendências declinantes ao longo do tempo, com o consequente crescimento da importância de outros setores. Mas esse fenômeno emerge particularmente quando a economia está num estágio avançado do desenvolvimento. Nas etapas iniciais desse processo, a atividade primária é a base da economia, e seu desenvolvimento é o que, em geral, motiva as transformações da estrutura produtiva.

Evidências empíricas e argumentos teóricos inferem que nas sociedades nas quais a atividade agrícola é arcaica, o processo de crescimento econômico também é ínfimo. Quando mudanças significativas em termos de técnicas de produção ocorrem no setor, elevando sua produtividade, a sociedade passa para um nível de desenvolvimento mais intenso.

Mas, mesmo tendo participação reduzida no desenvolvimento econômico, a agropecuária continua a ter um papel importante na economia, contribuindo com o fornecimento de matérias-primas e alimentos para o setor urbano-industrial, além de ser altamente demandante de insumos, máquinas e implementos, o que estimula a produção do setor industrial. Ademais, as divisas geradas pelas exportações da agropecuá- ria podem contribuir para o equilíbrio da balança comercial.

Nesse sentido, torna-se importante analisar o desempenho da agropecuária, sobretudo, na região Sul do Brasil (formada pelos estados do Paraná, de Santa Catarina e do Rio Grande do Sul). Isso porque, em comparação com as demais regiões do Brasil, o Sul detém uma das mais altas produtividades do País (FELEMA et al., 2013), apresentando uma participação elevada no valor agregado do setor, chegando a responder por 26\% do PIB agropecuário nacional (IPEADATA, 2016). Numa análise mais específica por produtos, a região se destaca como grande produtora de suínos e aves (49\% e $46 \%$ da produção brasileira em 2012, respectivamente), apresentando uma participação importante na produção de soja e milho, com destaque para o Paraná, que contribuiu com $19 \%$ e $21 \%$, respectivamente, de todo o valor bruto de produção destas culturas no âmbito nacional (IBGE, 2016).

Ademais, a atividade rural na região está distribuída entre a agricultura familiar e a empresarial, produzindo para o mercado interno e externo. No caso da agricultura familiar, tal segmento representa mais de $80 \%$ dos estabelecimentos tanto no Paraná quanto nos estados de Santa Catarina e do Rio Grande do Sul (IBGE, 2006). Atrelado a isso, do valor bruto de produção auferido pelo Sul em 2006, $43 \%$ originou- 
-se das atividades da agricultura familiar. Como tal categoria detinha apenas $31 \%$ da área rural sulina, isso demonstra a eficiência da agricultura familiar em retirar renda de uma menor área disponível. Nesse contexto, a agricultura familiar apresenta-se como importante na sustentação da agropecuária do Sul do País, e o seu sucesso não somente contribui para a produção de alimentos e matéria-prima em si, mas também é uma garantia de geração de trabalho e renda no campo.

Considerando o contexto acima exposto, o principal objeto deste estudo é analisar empiricamente se existe um processo de convergência da produtividade da agropecuária nas microrregiões da região entre 1995/96 e 2006 . Para tanto, em termos metodológicos, um modelo de convergência será estimado por meio das técnicas de econometria espacial. Isso porque acredita-se que a distribuição espacial da produtividade não seja aleatória, isto é, existe uma dependência espacial nessa variável. Assim, estimando-se o modelo empírico por meio do método de Mínimos Quadrados Ordinários (MQO), os resultados obtidos serão ineficientes e (ou) inconsistentes (ALMEIDA et al., 2008).

Por meio de uma Análise Exploratória dos Dados Espaciais (AEDE) confirmou-se a hipótese de que a distribuição espacial da produtividade não é aleatória, pelo contrário, existe uma correlação positiva nos dados. Isso significa que as microrregiões com elevada (baixa) produtividade são rodeadas por microrregiões com alta (baixa) produtividade. E, mediante a análise do mapa de clusters LISA, evidenciaram-se alguns agrupamentos locais (clusters) localizados principalmente no Rio Grande do Sul. Além disso, com a estimação do modelo empírico, confirmou-se a hipótese de que existe um processo de convergência, absoluta e condicional, da produtividade da terra na região Sul.

A principal contribuição deste trabalho para a literatura está no avanço quanto ao teste de convergência. No trabalho de Almeida et al. (2008) também se testou a convergência da produtivi-

6. Produtividade em termos monetários. dade média agrícola utilizando a econometria espacial; contudo, a investigação pairou apenas na convergência absoluta. A grande limitação dessa hipótese é que se assume que todas as regiões convergem para uma mesma produtividade, independentemente de suas características estruturais e iniciais. No caso brasileiro, o meio rural apresenta grandes diferenças, seja no âmbito do clima/solo, da estrutura produtiva, da assistência técnica, do grau de instrução dos produtores, da mecanização, dos insumos utilizados, do tamanho médio dos estabelecimentos, dentre outros elementos; assim, ao testar a suposição que todos os espaços tendem a convergir para o mesmo ponto, independente dessas características, distorce-se em alguma medida a realidade. Por isso, avança-se nesse sentindo, testando a convergência condicional e não apenas a absoluta.

Além desta introdução, o artigo possui outras quatro seções. Na seção 2, apresenta-se uma breve revisão da literatura acerca dos estudos sobre produtividade já realizados. Em seguida, na seção 3, discute-se a metodologia utilizada para testar a hipótese de convergência (absoluta e condicional) da produtividade da terra na região Sul. Na seção 4, realiza-se a análise dos resultados. Por fim, na seção 5, relatam-se as considerações finais do trabalho.

\section{Produtividade da agropecuária: elementos teóricos e empíricos}

Historicamente, o processo de desenvolvimento econômico tem-se manifestado de forma mais constante no setor industrial. Porém, não se deve desprezar o papel estratégico da agricultura, principalmente nos países subdesenvolvidos ou em desenvolvimento (RODRIGUES, 1978).

Com efeito, Bacha (2004) apresenta algumas funções da agricultura no processo de desenvolvimento industrial, tais como: fornecedora de poupança e divisas para indústria, bem como alimentos e matérias-primas; ser mercado consumidor (demandando tratores, máquinas, insumos, 
serviços etc.) e liberar mão de obra para o setor urbano-industrial. HWA (1988), constatou essa relação entre a agricultura e o setor industrial, de tal modo que o desenvolvimento agrícola induz o aumento da produtividade e, consequentemente, a fomentação do crescimento econômico.

Segundo Costa et al. (2013), o crescimento econômico é impulsionado pelos ganhos na produtividade agrícola e, assim, dependem de recursos como os naturais, humanos e de tecnologia agrícola. O rápido crescimento agrícola eleva a eficiência dos recursos de transferências entre os setores não agrícolas, resultando em um aumento da produtividade global da agricultura, do capital e do trabalho (HWA, 1988).

$\mathrm{Na}$ agricultura, o aumento da produtividade conduz a uma produção mais eficiente, podendo ser efetivada a custos menores por produto, gerando ganhos diretos para os agricultores, processadores e consumidores. No caso específico da agropecuária brasileira, o incremento da produtividade tem sido o principal fator responsável pelo crescimento do setor. No período entre 2000 e 2007 , cerca de $87 \%$ do crescimento do produto da agropecuária adveio do aumento da produtividade (AGROANALYSIS, 2008).

O crescimento agrícola relaciona-se diretamente com o padrão de consumo da população por meio de sua influência sobre os preços de alimentos. A redução dos preços e o aumento da disponibilidade de alimentos são promovidos pelos ganhos de produtividade agrícola. Nesse sentido, Alves (2010) destaca que o crescimento da produção é dependente, em boa medida, do crescimento da produtividade e, por isso, tem sido um crescimento que poupa a expansão das fronteiras agrícolas.

Segundo Brugnaro e Bacha (2009), a agropecuária brasileira aumentou sua participação na geração do PIB do Brasil de meados dos anos de 1990 a 2004. Os autores confirmaram que o crescimento da produtividade do trabalho no setor agropecuário contribuiu para o crescimento da participação da agropecuária no PIB brasileiro no período analisado, ressaltando que a produção agrícola também aumentou a partir de 1994, principalmente em decorrência do crescimento da área plantada e dos ganhos de produtividade.

Por reconhecer a importância da produtividade no setor agrícola, é possível encontrar na literatura diversos estudos que objetivaram analisar os seus determinantes. Felema et al. (2013) analisaram os determinantes da produtividade da terra e do trabalho na agropecuária brasileira em 2006 e observaram que a produtividade da terra e do trabalho nas regiões Sul e Sudeste apresentaram os melhores resultados, havendo uma correlação positiva entre elas. Isso sugere a existência de uma grande probabilidade de os melhores resultados da produtividade desses fatores estarem nos mesmos espaços geográficos. Os autores também observaram que a grande maioria dos municípios possuía um índice de produtividade baixo, ao passo que poucos tinham valores muito elevados.

Além do trabalho de Felema et al. (2013), encontram-se na literatura diversos estudos que analisaram a convergência da produtividade do setor agropecuário no Brasil, tais como: Lopes (2004), Phillips e Sul (2007), Fochezatto e Stülp (2008), Oliveira Junior et al. (2009), Barreto e Almeida (2009), Vicente (2011), Pena e Linhares (2013) e Almeida et al. (2008).

Com o intuito de testar e analisar a hipótese de convergência sob a perspectiva da produtividade da terra no Brasil em diferentes períodos entre 1960 e 2001, Lopes (2004) evidência esse processo para a produção de café, cana-de-açúcar, fumo, mandioca, laranja e soja, justificada pela difusão e pelas inovações tecnológicas existentes nessas culturas. No caso da convergência condicional, tal fato se constatou apenas para a batata, feijão e algodão, demonstrando um potencial de convergência quando se controla a deficiência hídrica e o capital humano.

Numa análise mais abrangente, investigando o setor da agropecuária como um todo, Fochezatto e Stülp (2008) analisaram a convergência da produtividade do trabalho dentre os estados brasileiros na década de 1990, usando cadeias de Markov. Os autores verificaram um aumento da produtividade em alguns estados, 
especialmente no Sudeste, Sul e Centro-Oeste. Ainda, identificaram que, entre os oito setores analisados, o setor agropecuário foi o que apresentou maior velocidade de convergência.

Nas suas projeções de curto e longo prazo obtidas pelo método de Markov, Fochezatto e Stülp (2008) diagnosticaram dois clubes de convergência: o primeiro formado preponderantemente pelos estados do Norte e Nordeste, convergindo para um nível de menor produtividade e, o segundo, formado principalmente pelos demais estados, convergindo para classes de maior produtividade. Essa constatação acerca da formação de dois grupos demonstrou o aprofundamento da disparidade que se teve na produtividade da mão de obra agrícola nos anos de 1990, resultado relacionado às condições econômicas prevalecentes naquela década.

Outro trabalho que identifica os clubes de convergência na agropecuária dos estados brasileiros é o de Pena e Linhares (2013). Nele, os autores utilizaram a metodologia proposta em Phillips e Sul (2007), a qual permite identificar clubes de convergência sob a hipótese de diversos tipos de heterogeneidade. Como no Brasil existem grandes diferenças climáticas e de solo, além de outras particularidades capazes de influenciar diferenciadamente o desempenho agropecuário dos estados e regiões, tal método se apresentou como adequado na investigação da convergência da agropecuária do País. Os resultados dos autores sugerem a formação de três grupos, validando igualmente a hipótese de $\beta$ - convergência.

Com uma metodologia alternativa, usando o modelo de fronteira não paramétrica (DEA) sob retornos constantes à escala, Vicente (2011) identificou uma amplitude de variação menor dos índices de produtividade total dos fatores e dos índices de eficiência econômica da agricultura em 2006 do que em 1995. Nesse sentido, como os menores índices de produtividade e eficiência estiveram mais próximos dos maiores níveis em 2006, o autor também inferiu acerca da existência de um processo de convergência destes índices entre os estados brasileiros.
Pontualmente, analisando apenas o estado do Ceará, Oliveira Junior et al. (2009) testaram a existência de um processo de convergência do PIB agrícola entre os seus municípios utilizando um modelo com efeito threshold para o período de 1970 a 1996. Comprovaram a hipótese de convergência, indicando a existência de quatro clubes. Para todos, tanto o capital humano como também o capital físico se mostraram importantes na determinação do processo de crescimento, com ressalva para a tecnologia que só se apresentou efetiva para o grupo de maior renda agrícola per capita e para o clube de renda intermediário.

Portanto, esses trabalhos corroboram quanto à existência de convergência na agropecuária do Brasil, e as características de cada região se apresentam como importantes nesse processo em praticamente todos os estudos. Nesse contexto, o uso da econometria espacial pode ser uma alternativa nesta investigação. Dentre os trabalhos brasileiros que estudam a convergência da produtividade na agricultura e que controlam os efeitos espaciais, citam-se Barreto e Almeida (2009) e Almeida et al. (2008).

No caso dos primeiros, os autores analisaram a influência dos investimentos em pesquisa agropecuária para o crescimento econômico dos estados brasileiros e para a convergência de renda agropecuária entre 1986 e 2004, utilizando um modelo econométrico de efeitos fixos, controlando a dependência espacial e a heterogeneidade espacial. Os resultados comprovaram a existência de um processo de convergência condicional, evidenciando a importância do capital físico agropecuário, da infraestrutura telefônica, da infraestrutura de armazenagem, do crédito rural, do número de trabalhadores rurais e das externalidades espaciais, para o crescimento do PIB per capita da agropecuária brasileira. Ademais, ressaltou-se a importância de P\&D agropecuário para a convergência de renda do setor.

Almeida et al. (2008) investigaram a evolução da produtividade agrícola das microrregiões brasileiras, analisando o grau de convergência absoluta entre 1991 e 2003. Por meio da econometria espacial, evidenciaram que, entre o período de 
1995-1999 e 2000-2003, a taxa de convergência obtida foi nula. Já entre 1991-1993, o processo de convergência ocorreu a passos lentos, com uma intensificação maior entre 1991-1994. Este último período teria contribuído decisivamente para a diminuição das desigualdades de produtividade no Brasil.

Diante dessa contextualização empírica, este trabalho agrega na discussão acerca da convergência da produtividade do setor primário do Brasil, contribuindo de duas maneiras:

1. no uso da econometria espacial, que pouco foi explorado nos trabalhos brasileiros, metodologia importante por considerar as características espaciais, os transbordamentos espaciais, na determinação da taxa de crescimento da produtividade;

2. na consideração da convergência condicional da produtividade da agropecuária, ultrapassando a hipótese que todas as regiões alcançarão a mesma produtividade independente de suas características iniciais e estruturais.

\section{Metodologia}

Como afirmado na introdução do trabalho, o objetivo central consiste em testar a hipótese de convergência (absoluta e condicional) da produtividade agropecuária na região Sul do Brasil". Um ponto importante a salientar é que as unidades de análise serão as microrregiões ${ }^{8}$. Nesse

7. Cabe destacar que o espaço sulino foi escolhido devido a sua importância dentro da produção da agropecuária nacional (em 2009, contribuiu com $26 \%$ do PIB da agropecuária brasileira, valor semelhante ao Sudeste, cuja participação foi de $27 \%$ ). Além disso, no trabalho de Felema et al. (2013) foi evidenciada a homogeneidade dos três estados sulinos no que se refere à produtividade da terra; essa característica minimiza eventuais problemas de inferência estatística por não estar se analisando clubes de convergência. Mesmo controlando fatores espaciais por meio da econometria espacial, elementos estruturais não estão sendo considerados, os quais podem ser minimizados por focar num espaço que não é tão discrepante.

8. A região Sul possui um total de 94 microrregiões, assim distribuídas: 39 no Paraná, 20 em Santa Catarina e 35 no Rio Grande do Sul. sentido, a ideia subjacente à análise é a de que quando uma determinada microrregião aumenta a sua produtividade, esse efeito não fica restrito a essa microrregião, mas sim, ocorre um transbordamento para as microrregiões circunvizinhas. Dessa forma, caso isso realmente venha a ocorrer, devem ser utilizadas técnicas econométricas que controlem esse efeito, para que os resultados obtidos não sejam ineficientes e (ou) inconsistentes (ALMEIDA et al., 2008). Assim, justifica-se a utilização das técnicas da econometria espacial.

\subsection{Análise da dependência espacial}

Como fora adiantado, acredita-se que a elevação da produtividade da terra em uma microrregião $i$ não fique restrita a essa microrregião, como também tem um efeito sobre a produtividade da terra da microrregião $j$. Em outras palavras, existe um efeito transbordamento na produtividade. Se isso realmente ocorrer, existirá uma dependência espacial entre as microrregiões $i$ e $j$, de maneira que a distribuição espacial da produtividade da terra não ocorra de forma aleatória. Diante disso, torna-se indispensável a realização de uma Análise Exploratória dos Dados Espaciais (AEDE).

Almeida (2012, p. 76) destaca que para realizar uma AEDE é necessário, primeiramente, a adoção de uma matriz de ponderação espacial $(W)$, em que essa é uma matriz quadrada de ordem $n$ por $n$, cujos elementos denotam o grau de conexão espacial entre as microrregiões da região Sul, seguindo algum critério de proximidade, como contiguidade e (ou) distância geográfica.

Na presente pesquisa, o critério de proximidade será baseado na contiguidade (com convenção do tipo torre e do tipo rainha ${ }^{9}$ ), em que se parte do pressuposto de que as microrregiões contíguas possuem uma interação mais forte do que as microrregiões que não são contíguas. Destaca-se que o elemento $w_{i j}$, da matriz de ponderação espacial $(W)$, terá valor igual a 1 quando

9. Para mais detalhes desses critérios, ver Almeida (2012, p. 76-79). 
duas microrregiões forem contíguas, e 0 em caso contrário.

Por convenção, o elemento $w_{i i}$ será igual a zero, tendo em vista que uma microrregião não poderá ser vizinha de si mesma. Como consequência, a diagonal principal da matriz de ponderação espacial $(W)$ terá apenas valores zeros. Além dessa, para se obter maior robustez nos resultados, também será utilizada uma matriz de peso espacial $(W)$ baseada no critério de proximidade dos $k$ vizinhos mais próximos, sendo este calculado pela métrica baseada no grande círculo entre os centros das microrregióes.

A análise exploratória dos dados espaciais utilizará as seguintes técnicas: testes de autocorrelação espacial global e local, em conjunto com a apresentação de mapas de clusters LISA.

\subsubsection{Autocorrelação espacial global}

A autocorrelação espacial global permite identificar se a distribuição espacial da produtividade da terra na região Sul ocorre de forma aleatória, ou não. Quando a hipótese de aleatoriedade é rejeitada, considera-se que a produtividade de uma determinada microrregião tem influência sobre a produtividade das microrregiões circunvizinhas. A análise da autocorrelação espacial será feita mediante a aplicação da estatística I de Moran (1948). A estatística I de Moran é definida da seguinte forma:

$$
I=\frac{n}{S_{0}} \frac{z^{\prime} W z}{z^{\prime} z}
$$

Em que $n$ denota o número de microrregiões; $z$ é o valor da produtividade da terra; $W z$ representa os valores médios das produtividades padronizadas nos vizinhos, definidos conforme a matriz de ponderação espacial adotada $(W)$; $S_{0}$ é o somatório de todos os elementos da matriz de ponderação espacial $(W)$.

A hipótese nula a ser testada é a de que a distribuição das produtividades da terra entre as microrregiões ocorre de forma aleatória, contra a hipótese alternativa de que essa distribuição é não aleatória. $\mathrm{O}$ valor esperado do teste é -[1/(n-1)]. Caso exista aleatoriedade na distribuição espacial, a estatística $I$ de Moran deve ser igual ao seu valor esperado, conforme o nível de significância adotado; caso contrário, rejeita-se a hipótese nula. Um valor de I maior do que o seu valor esperado indica uma autocorrelação espacial positiva, e um valor de $I$ abaixo do seu valor esperado indica uma autocorrelação espacial negativa.

Uma autocorrelação espacial positiva significa que as microrregiões que possuem uma produtividade da agropecuária elevada (baixa) são rodeadas por microrregiões que também possuem uma produtividade agropecuária elevada (baixa). Já na autocorrelação espacial negativa, as microrregióes que possuem uma produtividade agropecuária elevada (baixa) são rodeadas por microrregióes que possuem uma produtividade baixa (elevada).

\subsubsection{Autocorrelação espacial local}

Além da averiguação de autocorrelação global, como fora destacado anteriormente, também será feita uma análise acerca da possibilidade da existência de uma possível autocorrelação local. Almeida (2012, p. 120) advoga que essa análise é de suma importância, tendo em vista que a ausência de autocorrelação global pode ocultar padrões de autocorrelação local ou, ainda, uma forte indicação de autocorrelação global pode esconder outros padrões locais de autocorrelação.

Sendo assim, a autocorrelação espacial local será averiguada por meio da estatística I de Moran local, a qual é formalizada da seguinte forma:

$$
I_{i}=z_{i} \sum_{j=1}^{J} w_{i j} z_{j}
$$

Em que $z_{i}$ corresponde o valor da produtividade agropecuária da microrregião $i$ padronizada; $w_{i j}$ denota o elemento da matriz de ponderação espacial $(W)$ e $z_{j}$ é o valor da produtividade agropecuária da microrregião $j$ padronizada. Assumindo a condição de normalidade, o valor esperado da estatística $I_{i}$ será: $E\left[I_{i}\right]=-w_{i} /(n=1)$. 
Vale frisar que a análise da estatística $I_{i}$ de Moran local é muito mais complexa do que a análise do I de Moran global. Isso porque, na análise local, cada observação possuirá a sua estatística $I_{i}$, obtendo-se, assim, $n$ computações da estatística $I_{i}$ com os seus respectivos níveis de significância, o que torna impossível analisá-las separadamente. Dessa forma, com o intuito de facilitar a análise deste amplo conjunto de informações, utilizar-se-á o mapa de cluster do tipo LISA (Local Indicator of Spatial Association), que exibe apenas os municípios que possuem os $I_{i}$ de Moran significativos.

\subsection{Modelo empírico e variáveis}

O modelo que será utilizado para testar a hipótese de convergência (absoluta e condicional) da produtividade da agropecuária na região Sul do Brasil segue a mesma lógica do modelo utilizado para a análise da convergência de renda, sendo que, ao invés da variável renda, utilizar-se-á a variável produtividade da agropecuária. Nesse caso, como o modelo é amplamente difundido na literatura, convém apresentar apenas os seus fundamentos principais.

\subsubsection{Modelo empírico}

O modelo aqui descrito segue os estudos de Barro e Sala-i-Martin (1995), Martin e Sunley (2000), Almeida et al. (2008). De forma geral, os citados estudos utilizaram os conceitos de convergência $\beta$ (beta) e $\sigma$ (sigma). O teste $\beta$ (convergência absoluta) é realizado por meio da regressão do logaritmo natural da razão obtida da divisão da produtividade agropecuária $(P T)$ do período $t+n$ pela produtividade agropecuária do período $t$, isto é:

$$
\ln \left(\frac{P T_{t+n}}{P T_{t}}\right)=\alpha+\beta \ln P T_{t}+u
$$

Em que $\alpha$ e $\beta$ serão os parâmetros a serem estimados e $u$ é o termo de erro aleatório. Nesse modelo, caso exista a convergência da produtividade agropecuária, o coeficiente associado ao parâmetro $\beta$ deve ter sinal negativo e estatisticamente significativo.

Almeida e Guanziroli (2013) destacam que, para que a convergência seja validada, é necessário que a variação da produtividade (medida por $\alpha$ ) dentre as microrregióes avaliadas diminua com o passar do tempo. Desse modo, a convergência $\beta$ conduz a uma dispersão decrescente, ou convergência $\alpha$. Todavia, a convergência $\alpha$ é influenciada pelo termo de erro, ou por choques na regressão do crescimento, podendo fazer com que $\beta$ diminua e $\alpha$ aumente. Por conta disso, diz-se que a convergência $\beta$ é uma condição necessária, mas não suficiente, para a convergência $\alpha$.

Caso a situação acima descrita se confirme, entende-se que a produtividade não se direciona para uma situação de estado estacionário comum, ou seja, igual para todas as microrregiões, mas sim para as posições relativas de estado estacionário. Nesse caso, considera-se que a convergência é condicional, pois depende das características estruturais das microrregiões, as quais são distintas; de forma que distintas localidades terão diferentes produtividades relativas de estado estacionário condicionadas por X (em que $X$ é um vetor de variáveis estruturais) (ALMEIDA e GUANZIROLI, 2013). Nessa situação, o modelo a ser estimado possui a seguinte especificação:

$$
\ln \left(\frac{P T_{t^{+n}}}{P T_{t}}\right)=\alpha+\beta_{1} \ln P T_{t}+\beta_{2} \ln X+u
$$

Cabe aqui salientar que, caso exista alguma dependência espacial entre as microrregiões analisadas, a estimação dos modelos empíricos especificados nas equações (3) e (4), por Mínimos Quadrados Ordinários (MQO), resultará em resultados inconsistentes e/ou ineficientes. Desse modo, os modelos de convergência anteriormente formalizados devem ser estimados por meio das técnicas analíticas da econometria espacial.

Encontram-se na literatura alguns estudos que estimaram o modelo de convergência com as técnicas de econometria espacial, como no trabalho de convergência de renda de Rey e Montouri (1999). Barreto e Almeida (2008) estimaram o modelo de 
convergência, com dependência espacial, para analisar a contribuição do capital humano para o crescimento econômico e para a convergência de renda no estado do Ceará. Almeida e Guanziroli (2013) utilizaram tal modelo para testar a convergência das taxas de homicídios no estado de Minas Gerais. Já Almeida et al. (2008) analisaram a convergência espacial da produtividade da terra para as microrregiões brasileiras.

$\mathrm{Na}$ análise espacial da convergência, Florax et al. (2003) descrevem um breve roteiro a ser seguido para a especificação do modelo empírico, composto pelos seguintes passos: I) estimar o modelo de convergência pelo método MQO; II) testar se há, ou não, autocorrelação espacial, devido a uma defasagem ou a um erro, por meio do valor do Multiplicador de Lagrange para defasagem espacial $\left(M L_{\rho}\right)$ e Multiplicador de Lagrange para o erro espacial $\left(M L_{\lambda}\right)$; III) caso a autocorrelação não seja confirma em ambos os testes, estima-se o modelo de convergência por MQO, caso contrário, segue-se ao próximo passo; IV) caso ambos os testes sejam estatisticamente significantes, deve-se estimar o modelo que apresentou o maior valor, conforme as versões robustas desses testes; ou seja, o Multiplicador de Lagrange Robusto para a defasagem espacial $\left(M L R_{\rho}\right)$ e o Multiplicador de Lagrange Robusto para o erro espacial $\left(M L R_{\lambda}\right)$. Nesse caso, se $M L R_{\rho}>M L R_{\lambda} \mathrm{o}$ modelo com defasagem espacial é o mais indicado, se $M L R_{\rho}<M L R_{\lambda}$, o modelo de erro espacial será o mais apropriado.

Caso o modelo mais apropriado seja o de defasagem espacial (denominado modelo SAR), os modelos de convergência espacial assumem as seguintes formas:

$\ln \left(\frac{P T_{t+n}}{P T_{t}}\right)=\alpha+\rho W\left[\ln \left(\frac{P T_{t+n}}{P T_{t}}\right)\right]+\beta \ln P T_{t}+\varepsilon$

$\ln \left(\frac{P T_{t+n}}{P T_{t}}\right)=\alpha+\rho W\left[\ln \left(\frac{P T_{t+n}}{P T_{t}}\right)\right]+$

$+\beta_{1} \ln P T_{t}+\beta_{2} \ln X+\varepsilon$

Nesses modelos, $\rho$ é o coeficiente de defasagem espacial (um escalar) e $W$ é a matriz de ponderação espacial adotada, que fora especi- ficada na subseção anterior. Nesse caso, a variável $W\left[\ln \left(\frac{P T_{t+n}}{P T_{t}}\right)\right]$ pode ser interpretada como sendo a média do valor da variável $\ln \left(\frac{P T_{t+n}}{P T_{t}}\right)$ nas microrregiões vizinhas.

Por outro lado, se a dependência espacial for manifestada no erro (denominado modelo SEM), os modelos de convergência espacial assumem as seguintes formas:

$$
\ln \left(\frac{P T_{t+n}}{P T_{t}}\right)=\alpha+\beta \ln P T_{t}+\xi
$$

$\xi=\lambda W \xi+\varepsilon$

$$
\ln \left(\frac{P T_{t+n}}{P T_{t}}\right)=\alpha+\beta_{1} \ln P T_{t}+\beta_{2} \ln X+\xi
$$

$\xi=\lambda W \xi+\varepsilon$

Além do modelo de defasagem espacial e do erro espacial, considerou-se também a possibilidade de transbordamento espacial das variáveis explicativas. Neste caso, outros dois modelos foram testados: o Durbin espacial (SDM) e o Durbin espacial do erro (SDEM).

No modelo de Durbin espacial (SDM) é incluído, dentre as variáveis explicativas, um componente de transbordamento espacial WX, bem como a variável dependente defasada, conforme (9) e (10).

$$
\begin{aligned}
& \ln \left(\frac{P T_{t+n}}{P T_{t}}\right)=\alpha+\rho W\left[\ln \left(\frac{P T_{t+n}}{P T_{t}}\right)\right]+ \\
& +\pi_{1} \ln P T_{t}+\pi_{2} W\left[\ln \left(P T_{t}\right)\right]+\varepsilon \\
& \ln \left(\frac{P T_{t+n}}{P T_{t}}\right)=\alpha+\rho W\left[\ln \left(\frac{P T_{t+n}}{P T_{t}}\right)\right]+\pi_{1} \ln P T_{t}+ \\
& +\pi_{2} \ln X+\pi_{3} W\left[\ln \left(P T_{t}\right)\right]+\pi_{4} W[\ln (X)]+\varepsilon
\end{aligned}
$$

Já no modelo de Durbin espacial do erro (SDEM), incorporam-se componentes espaciais de alcance local, que se manifestam nas variáveis explicativas exógenas, e componentes espaciais que afetam o termo de erro (11) e (12).

$$
\ln \left(\frac{P T_{t+n}}{P T_{t}}\right)=\alpha+\tau_{1} \ln P T_{t}+\tau_{2} W\left[\ln \left(P T_{t}\right)\right]+\xi
$$

$\xi=\lambda W \xi+\varepsilon$ 


$$
\begin{aligned}
& \ln \left(\frac{P T_{t^{+n}}}{P T_{t}}\right)=\alpha+\tau_{1} \ln P T_{t}+\tau_{2} \ln X+ \\
& +\tau_{3} W\left[\ln \left(P T_{t}\right)\right]+\tau_{4} W[\ln (X)]+\xi
\end{aligned}
$$

$\xi=\lambda W \xi+\varepsilon$

É importante destacar que, no caso do modelo SAR e SEM, os testes do tipo Multiplicador de Lagrange conseguem definir qual é o melhor modelo. Contudo, para o modelo de Durbin espacial (SDM) e de Durbin espacial do erro (SDEM), tais testes não são apropriados. Nestes casos, um procedimento mais geral, conforme destacado por Tyszler (2006 apud ALMEIDA, 2012, p. 236), considera o melhor modelo como sendo aquele que apresentar o menor valor do critério de informação.

\subsubsection{Variáveis}

Como o objetivo do presente trabalho é testar a hipótese de convergência (absoluta e condicional) da produtividade agropecuária da região Sul do Brasil, deve-se definir a forma de mensuração dessa variável. Nos modelos descritos na subseção 3.2.1., $P T_{t}$ será a produtividade agropecuária (ou também chamada de produtividade da terra) da microrregião $i$ em 1995/96, enquanto $P T_{t+n}$ é a produtividade agropecuária dessa microrregião em 2006. No presente trabalho, o cálculo da referida variável está em linha com as metodologias empregadas nos estudos de Hoffman e Jamas (1990), Guerreiro (1995) e Felema et al. (2013), formalizada da seguinte forma:

$$
\begin{aligned}
V A_{i} & =V B P_{i}-C I_{\mathrm{i}} \\
P T_{i} & =\frac{V A_{i}}{A T E_{i}}
\end{aligned}
$$

Isto é, por meio da equação (13) calcula-se o Valor Agregado para cada microrregião ${ }^{10} i\left(V A_{i}\right)$, subtraindo-se os Custos Intermediários ${ }^{11}\left(C I_{i}\right)$ do

10. A região Sul possui um total de 94 microrregiões, sendo 39 no Paraná, 35 no Rio Grande do Sul e 20 em Santa Catarina.

11. No cálculo do custo intermediário foram considerados os gastos com adubos e corretivos; sementes e mudas; agrotóxicos; medicamentos para animais; alimentação dos
Valor Bruto da Produção ${ }^{12}\left(V B P_{i}\right)$. Posteriormente, a razão obtida da divisão do Valor Agregado $\left(\mathrm{VA}_{\mathrm{i}}\right)$ e da Área Total Explorada ${ }^{13}\left(A T E_{i}\right)$ será a Produtividade Agropecuária da microrregião $i$ $\left(P T_{i}\right)$. Ressalta-se que todas as variáveis até aqui utilizadas são procedentes dos censos agropecuários de 1995/1996 e de 2006, ambos realizados pelo Instituto Brasileiro de Geografia e Estatística (IBGE). Ademais, os dados de 2006 foram deflacionados pelo IGP-DI e os dados de 1995 foram igualados a $100 .{ }^{14}$

Já o conjunto de variáveis estruturais, representadas pelo vetor $X$, nos modelos formalizados na subseção 3.2.1., será composto pelas seguintes variáveis: área explorada (Área); mão de obra por hectare (L); percentual de estabelecimento com assistência técnica regular (Assis.); máquinas e implementos agrícolas por hectare (Maq.); tratores por hectares (Trat.); custo com insumos (R\$/hectare - Ins.); percentual da área explorada destinada à pecuária (Pec.); índice de Gini da distribuição da terra (Gini) ${ }^{15}$.

\section{Análise dos resultados}

Nesta seção, apresenta-se a análise dos resultados. Primeiramente, na subseção 4.1 discute-se a distribuição espacial da produtividade agropecuária na região Sul do Brasil, por meio da AEDE.

animais (sal, rações industriais e outros alimentos); ovos fertilizados de um dia e pintos; aluguel de máquinas e equipamentos; transporte da produção; sacaria e outras embalagens; combustíveis e lubrificantes; energia elétrica e outras despesas).

12. O IBGE (2010) considera, para o cálculo do valor bruto de produção agropecuária, o seguinte: produção animal de grande porte, médio porte, aves e pequenos animais; produção vegetal, lavouras permanentes, lavouras temporárias, horticulturas, floricultura, silvicultura e extração vegetal; e agroindústria

13. ATE é definida como a área em estabelecimentos agrícolas, desconsiderando-se as terras inaproveitáveis.

14. Outros autores, como Santos e Guerreiro (2005) e Alvin e Dimonde (2010), também utilizam um único deflator para todas as regiões analisadas.

15. Este índice de Gini foi calculado considerando o número de estabelecimentos rurais e a área total em cada faixa de área que é estabelecido pelo próprio censo agropecuário. 
Em seguida, na subseção 4.2, analisam-se os resultados obtidos da estimação do modelo empírico, ou seja, testa-se a hipótese de convergência (absoluta e condicional) da produtividade agropecuária na região Sul.

\subsection{Distribuição espacial da produtividade da agropecuária na Região Sul do Brasil}

Na Figura 1 apresenta-se a evolução da Produtividade da Agropecuária $(P T)$ na região Sul do Brasil. Na média, a produtividade, em 1995/96, era de $\mathrm{R} \$ 276,00 /$ ha e passou para $\mathrm{R} \$$ 743,00/ha, em 2006 ${ }^{16}$. Embora a produtividade média da região se apresente alta quando comparado aos demais estados, como demonstrado no trabalho de Felema et al. (2013), internamente, grandes desigualdades são verificadas. Em 2006, enquanto algumas microrregiões alcançaram um valor igual a $\mathrm{R} \$ 2.269,00 / \mathrm{ha}$, outras atingiram apenas R\$164,00/ha. Particularmente, a região que vai do sul até o sudoeste do Rio Grande do Sul existe um dos maiores vazios quanto à eficiência produtiva, a qual perdura e está se ampliando no decorrer dos anos (1995/96 para 2006). No Paraná também se encontram microrregiões com baixa PT, principalmente nas microrregióes localizadas entre o extremo sul estendendo-se até o norte pioneiro.

16. A taxa de crescimento média da produtividade entre esses dois períodos analisados foi bastante elevada. Três potenciais explicações podem justificar tal aumento (BACHA, 2011): 1) teve uma elevação significativa da modernização da agropecuária do Brasil nesse período, em que, só no caso do uso de fertilizantes o consumo passou de $110,2 \mathrm{~kg} / \mathrm{ha}$ para $350,6 \mathrm{~kg} / \mathrm{ha}$, potencializando a produtividade por área produzida; 2) a pecuária apresentou um crescimento bastante forte, elevando a produção no transcorrer do período analisado, com destaque especial para as aves, que aumentaram em mais de $500 \%$ sua produção entre 1985 e 2008. Dessa forma, como a região Sul é responsável por boa parte desta produção $(46 \%)$, certamente isso intensificou a receita obtida por área, haja vista que tal atividade (avicultura) demanda pequenas áreas para se efetivar sua produção. O mesmo ocorreu com a suinocultura, que também teve ganhos significativos de produção, a qual também demanda áreas pequenas, destacando novamente a importância do Sul nesta produção (49\%). 3) por fim, especialmente a partir de 2001 elevou-se significativamente a exportação da agropecuária brasileira, beneficiada pela expansão da demanda mundial.
Figura 1. Produtividade da terra (PT) das microrregiões da região Sul do Brasil em 1995 e 2006

(a)

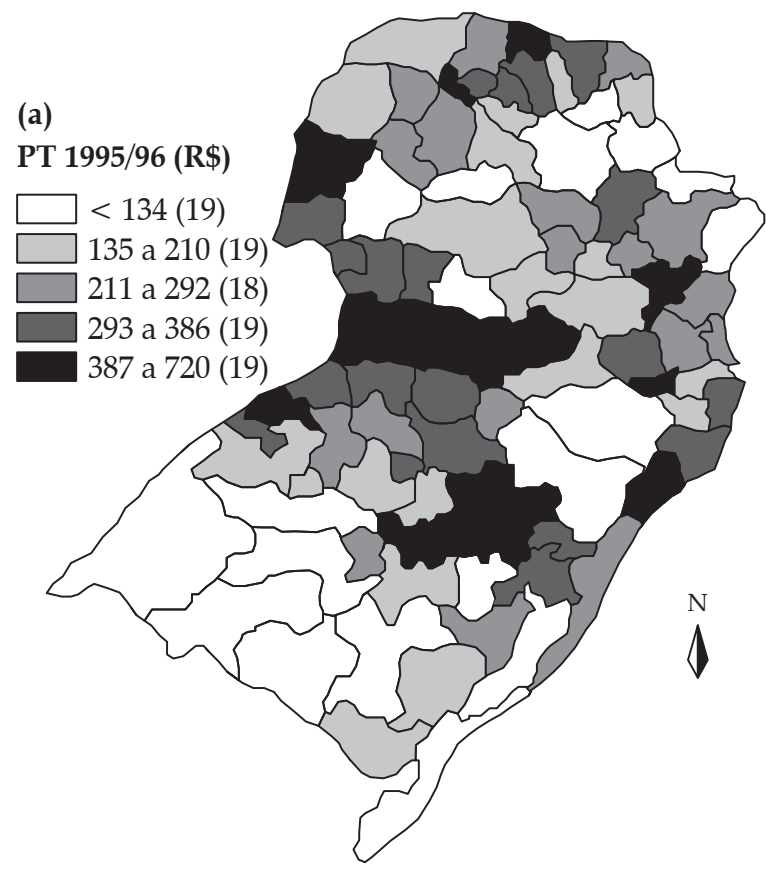

(b)

\section{PT 2006}

$(\mathrm{R} \$-1995=100)$
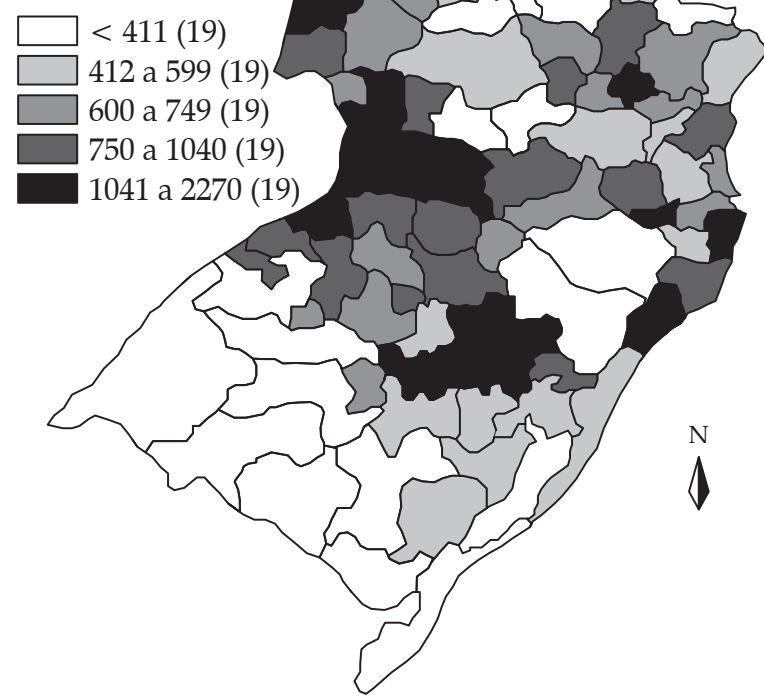

Fonte: Resultado da pesquisa.

Um ponto importante a ser destacado é que, ao analisar a evolução individual (Figura 2), se nota uma melhora da produtividade da agropecuária em praticamente todas as microrregiões. 
Mais do que isso, verifica-se que muitas microrregiões que possuíam uma produtividade bastante baixa no período inicial conseguiram auferir taxas de crescimento elevadas, passando a ideia de que existe um processo de homogeneização da produtividade na região Sul do País.

Figura 2. Taxa de crescimento da produtividade da terra microrregiões da região Sul do Brasil - entre $1995 / 96$ e 2006

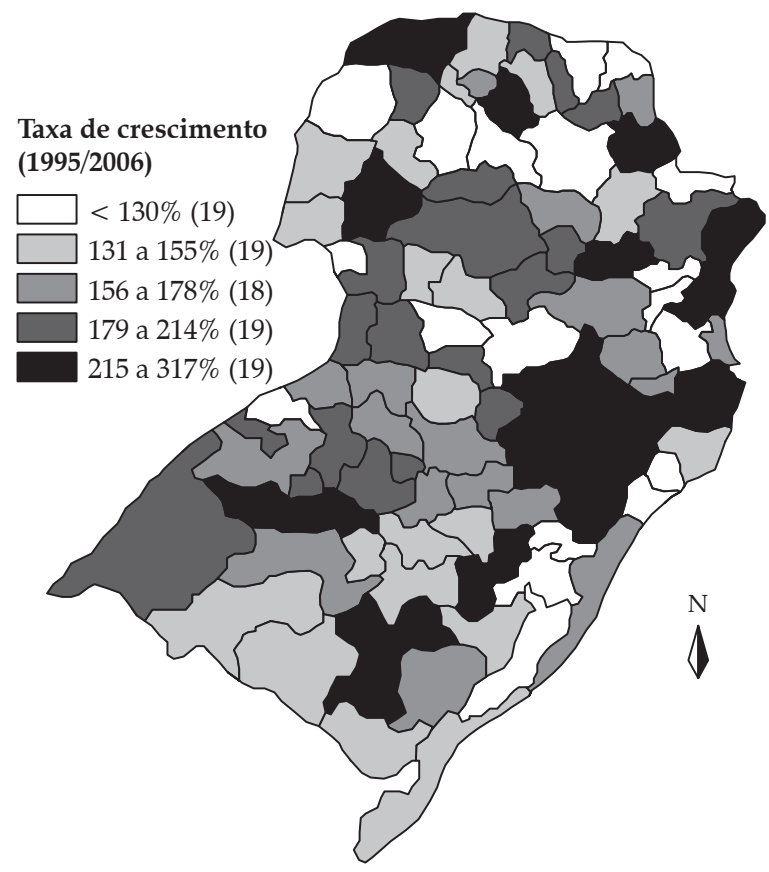

Fonte: Resultado da pesquisa
Em termos de distribuição espacial da produtividade agrícola, por meio da estatística do I de Moran (Tabela 1), se constata a existência de um padrão de associação espacial que independe da matriz de pesos utilizada, demonstrando a robustez dos resultados. Com efeito, evidencia-se uma autocorrelação espacial positiva, revelando similaridade entre os valores e a localização espacial das microrregiões. Ou seja, as microrregiões com elevada produtividade da agropecuária estão rodeadas por microrregiões com também elevada produtividade, ao passo que microrregiões com baixos valores tendem a estar rodeadas por vizinhos que também apresentam baixos níveis de produtividade na agropecuária. Portanto, percebe-se um efeito de transbordamento da produtividade, da mesma forma que se observa um contágio da sua carência. E o mais interessante é que persiste e se intensifica esse fenômeno no decorrer dos anos, como pode ser observado pelo crescimento do I de Moran.

Em Lopes (2004) são destacados três fatores que podem contribuir para a associação espacial da produtividade da agropecuária (da terra). Primeiro, a ocorrência de mudanças estruturais no processo de produção (vinculadas, principalmente, às inovações tecnológicas e/ou incentivadas por políticas públicas). Segundo, o fenômeno da difusão tecnológica (de novas sementes, de novos sistemas de plantio ou de novos implemen-

Tabela 1. Coeficiente I de Moran para PT - 1995/96 e 2006 - microrregião do Sul do Brasil

\begin{tabular}{lcccc}
\hline \multirow{2}{*}{ Convenção } & \multicolumn{2}{c}{ 1995/1996 } & \multicolumn{2}{c}{$\mathbf{2 0 0 6}$} \\
\cline { 2 - 5 } & Valor & p-valor & Valor & $p$-valor \\
\hline Rainha de 1 ordem & 0,24 & 0,00 & 0,31 & 0,00 \\
Torre de 1 ordem & 0,23 & 0,00 & 0,30 & 0,00 \\
3 vizinhos mais próximos & 0,35 & 0,00 & 0,36 & 0,00 \\
4 vizinhos mais próximos & 0.27 & 0,00 & 0,32 & 0,00 \\
5 vizinhos mais próximos & 0,22 & 0,00 & 0,27 & 0,00 \\
\hline
\end{tabular}

Nota: Pseudo-significância empírica baseada em 999 permutações aleatórias.

Fonte: Resultado da pesquisa. 
tos agrícolas). Terceiro, a eliminação de obstáculos ao crescimento da produção (como restrições ambientais, falta de adequada logística e carência de financiamento etc.). Destaca-se que esses fatores podem afetar o conjunto das microrregiões, ou, ainda, podem afetar de forma mais intensa algumas localidades, implicando uma associação espacial local, como demonstrado na Figura 3.

Na Figura 3 é apresentado o mapa de clusters LISA $^{17}$. Nota-se que em 1995/96 se evidenciam dois principais clusters em toda a região Sul, sendo um localizado no leste do Rio Grande do Sul, composto por quatro microrregiões, e representando um agrupamento alto-alto da produtividade; e o outro identificado no extremo do Rio Grande do Sul, composto por oito microrregiões, cuja característica era de baixo-baixo. No decorrer dos anos, continuou a permanência desses dois clusters, com a ampliação do segundo, formando um terceiro aglomerado principal cuja característica era baixo-alto (com seis microrregióes).

Um dos elementos que potencialmente justifica a existência desses dois conglomerados - baixo-baixo e baixo-alto - no Rio Grande do Sul é a arenização ${ }^{18}$ presente em algumas áreas do estado, como destaca Suertegaray (2011). Tal fenômeno é decorrente de processos naturais, podendo ser intensificado pelas atividades humanas. Segundo o autor, a presença de água por meio de processos de escoamento concentrado do tipo ravinas foi o agente natural. No entanto, em determinadas regiões, a arenização se intensificou em virtude da expansão da lavoura de soja e da diminuição das áreas pastoris, elementos que provocaram o sobrepastoreio, particularmente entre 1960 até meados de 1980, quando a cultura da soja, por decorrência dessa mesma "degradação" de terras, foi se reduzindo em área. Recentemente, o que se verifica é um retorno ao plantio da soja em áreas suscetíveis à arenização. Nesse contexto, e conforme os resul-

17. A partir daqui, a matriz de pesos utilizada tanto na AEDE como na econometria espacial será "quatro vizinhos", por tal convenção apresentar o maior I de Moran dos resíduos.

18. Arenização refere-se ao retrabalhamento de depósitos areníticos (pouco consolidados) ou arenosos (não consolidados). tados das Figuras 1 e 2, é necessário efetivar ações que venham a combater tal processo, mitigando o fenômeno, para que não se elevem ainda mais as áreas de terras improdutivas.

Figura 3. Mapa de clusters para a produtividade da terra - microrregiões do Sul do Brasil - 1995/1996 (a) e 2006 (b)

(a)
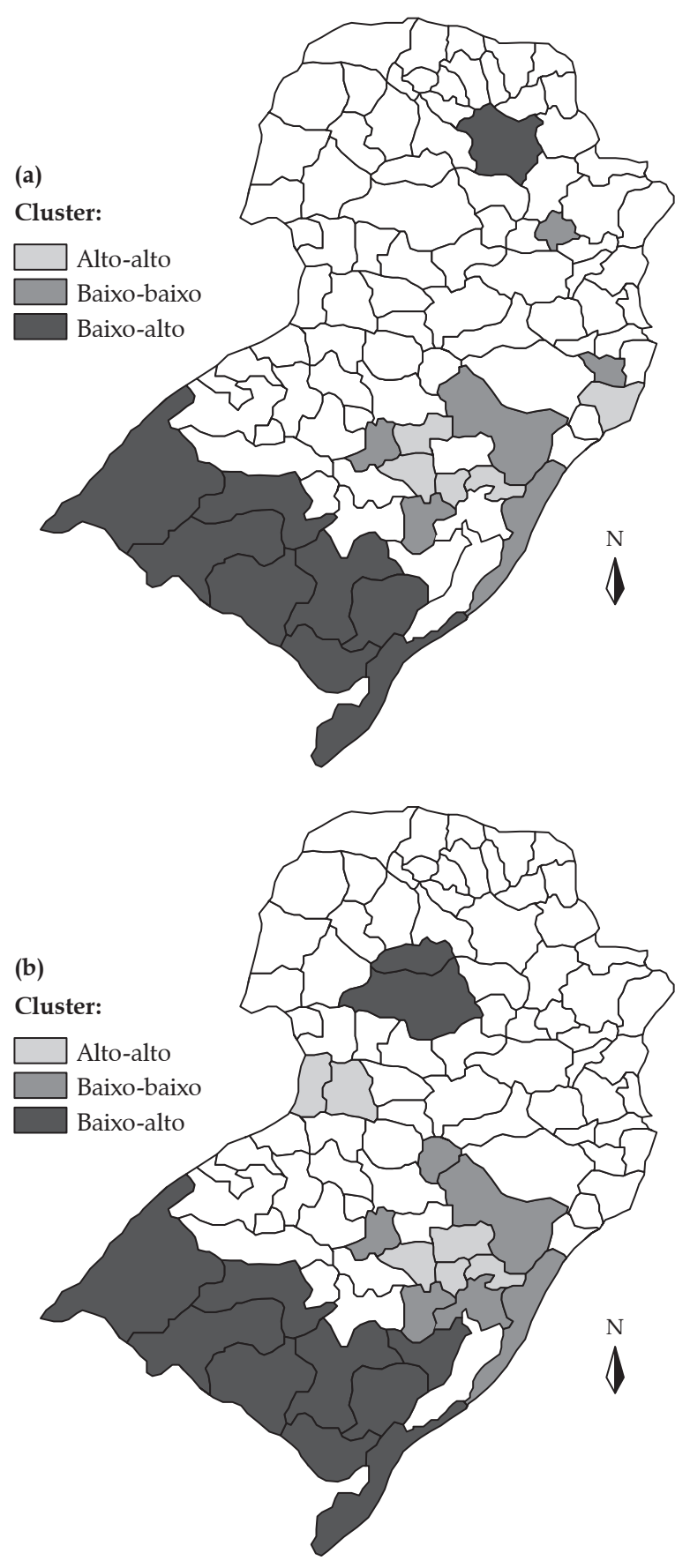

Fonte: Resultado da pesquisa. 


\subsection{Convergência da Produtividade da Agropecuária no Sul do Brasil}

Considerando as características apresentada na seção anterior - na qual todas as microrregiões melhoraram sua PT -, a existência de um processo de convergência implica diretamente produções cada vez maiores, homogeneizando a eficiência ao longo de todo o espaço. E é por isso que o seu diagnóstico é de suma relevância.

A Tabela 2 apresenta os resultados quanto à convergência absoluta da produtividade da agropecuária no Sul do Brasil. Mediante as análises dos testes baseados no multiplicador de lagrange e no multiplicador de lagrange robusto, se constatou que o modelo SEM é o mais apropriado; porém, tal modelo apresentou erros heterocedásticos (teste Koenker-Basset igual a 14,8; significativo ao nível de 1\%), tornando necessária a utilização do estimador de Kelejian e Prucha (2010) ${ }^{19}$.

Nos resultados, o coeficiente que acompanha a produtividade inicial (Ln PT 95/96) apresentou sinal negativo e significância estatística ao nível de $1 \%$, ou seja, na média, aquelas microrregiões que tinham uma PT menor em 1995/96 obtiveram uma taxa de crescimento mais alta no período subsequente. Isso significa que existe um processo de diminuição das desigualdades regionais em curso, proporcionando um desempenho da agropecuária mais equitativo para toda a região Sul do Brasil.

Concomitantemente, o efeito espacial (representado pelo parâmetro $\lambda$ ) também foi estatisticamente significativo. Destarte, os efeitos sobre a produtividade não procedem apenas do choque (representado pelo termo erro) de uma região, mas também do transbordamento de choque oriundos de outras microrregiões vizinhas. Ou seja, os efeitos não modelados apresentam uma autocorrelação espacial positiva. Assim, o melhoramento da produtividade de uma determinada microrregião não depende apenas das suas ações, mas também do comportamento da produtividade das microrregiões do seu envoltó-

19. Modelo SEM e SDEM estimados via Método dos Momentos Generalizado (GMM) rio que, de alguma maneira, influenciam na sua produtividade.

No caso da estimativa do modelo de Durbin espacial (Tabela 2, modelo 4 e 5), conforme o critério de informação Akaike e Schwarz, o modelo mais apropriado foi o SDEM. Com efeito, ao adicionar a defasagem espacial da variável explicativa (LnW PT) não se teve alteração no resultado, tendo em vista que o coeficiente que testa a convergência continua negativo e estatisticamente significativo, indicando a existência de um processo de homogeneização da produtividade na região. Ao mesmo tempo, o coeficiente que avalia a defasagem espacial da produtividade inicial apresentou sinal positivo e significância estatística, isso quer dizer que uma microrregião que está cercada por outras microrregiões com produtividades iniciais elevadas tende a apresentar uma alta taxa de crescimento da sua produtividade.

Em suma, na análise da convergência absoluta é possível constatar a ocorrência de um processo de convergência da produtividade da agropecuária, e que esse resultado é robusto, haja visto que independe do modelo espacial estimado. Além de haver um processo de convergência na região, existe também uma influência espacial na determinação da produtividade da agropecuária, inferindo que políticas de intensificação da produtividade não são eficientes se tomadas somente num olhar local, tendo melhores resultados se ocorrerem no âmbito regional.

Porém, como as microrregiões apresentam características estruturais que são díspares, não necessariamente todas elas chegariam ao mesmo ponto de convergência da produtividade da agropecuária. Ou seja, as microrregiões que são idênticas nas suas características convergem, no longo prazo, independente da sua condição inicial; porém, como existem diferenças estruturais entre as regiões (como tecnologia, característica da atividade produtiva etc.), elas podem convergir para diferentes estados estacionários. Embasados nisso, muitos autores criticam o modelo de convergência absoluta, admitindo que suas conclusões são fracas (SOUZA e PORTO JUNIOR, 2002). 
Tabela 2. Resultado dos modelos de erro espacial (SEM), defasagem espacial (SAR), Durbin espacial do erro (SDEM) e Durbin espacial (SDM) para a convergência absoluta

\begin{tabular}{|c|c|c|c|c|c|}
\hline \multirow{2}{*}{ Variáveis } & \multicolumn{5}{|c|}{ Modelos } \\
\hline & MQO (1) & SAR (2) & SEM (3) & SDM (4) & SDEM (5) \\
\hline Constante & $\begin{array}{c}3,949^{*} \\
(0,00)\end{array}$ & $\begin{array}{l}4,880^{*} \\
(0,02)\end{array}$ & $\begin{array}{c}4,438^{*} \\
(0,00)\end{array}$ & $\begin{array}{l}-0,196 \\
(0,79)\end{array}$ & $\begin{array}{l}0,197 \\
(0,72)\end{array}$ \\
\hline Ln PT 95/96 & $\begin{array}{c}-0,623^{*} \\
(0,00)\end{array}$ & $\begin{array}{l}-0,468 \\
(0,11)\end{array}$ & $\begin{array}{c}-0,714^{*} \\
(0,00)\end{array}$ & $\begin{array}{l}-0,875 \\
(0,00)\end{array}$ & $\begin{array}{c}-0,816^{*} \\
(0,00)\end{array}$ \\
\hline Ln W PT95/96 & - & - & - & $\begin{array}{l}0,905 \\
(0,00)\end{array}$ & $\begin{array}{c}0.857^{*} \\
(0,00)\end{array}$ \\
\hline$\lambda$ & - & - & $\begin{array}{l}0,308^{*} \\
(0,00)\end{array}$ & - & $\begin{array}{c}-0,167^{* *} \\
(0,08)\end{array}$ \\
\hline$\rho$ & - & $\begin{array}{l}-3,34 \\
(0,15) \\
\end{array}$ & - & $\begin{array}{l}0,840 \\
(0,14) \\
\end{array}$ & \\
\hline $\mathrm{R}^{2}$ & 0,41 & 0,15 & 0,41 & 0,45 & 0,53 \\
\hline I Moran do resíduo & $2,15^{*}$ & $0,31^{*}$ & $-0,08$ & $-0,25^{*}$ & $-0,07$ \\
\hline Crit. informação Akaike & - & - & - & 203,65 & 201,45 \\
\hline Crit. Schwarz & - & - & - & 213,82 & 209,08 \\
\hline ML $\rho$ (defasagem) & 0,37 & - & - & - & - \\
\hline MLR $\rho$ (defasagem robusta) & $18,66^{*}$ & - & - & - & - \\
\hline ML $\lambda$ (erro) & $3,65^{* *}$ & - & - & - & - \\
\hline MLR $\lambda$ (erro robusto) & $21,93^{*}$ & - & - & - & - \\
\hline
\end{tabular}

Nota: Entre parênteses refere-se ao p-valor. * Significativo a um nível de significância de 5\%; ** Significativo a um nível de significância de $10 \%$. PT95/96 refere-se à produtividade da terra de 1995/1996; $\lambda$ é o parâmetro do erro autorregressivo espacial; $\rho$ é o coeficiente autorregressivo espacial; $W$ é um vetor $n x 1$ de defasagens espaciais; Ln é o logaritmo; ML refere-se ao multiplicador de lagrange.

Fonte: Resultado da pesquisa.

Dessa forma, um novo teste foi realizado, utilizando a ideia de convergência condicional. Com isso, acrescentou-se nas regressões da Tabela 2 um conjunto de variáveis explicativas (variáveis de controle). Nessa nova rodada de estimações, os testes do tipo multiplicador de lagrange e de multiplicador de lagrange robusto continuaram a indicar o modelo SEM como o mais apropriado, ressaltando que tal estimativa não apresentou erros heterocedásticos (teste Koenker-Basset igual a 10,7). Esses novos resultados estão reportados na Tabela 3.

Com a inclusão desse grupo de variáveis, o coeficiente estimado da produtividade inicial (Ln PT95/96) continuou negativo e estatisticamente diferente de zero, evidenciando, assim, um processo de convergência condicional. Além disso, esse processo de convergência da produtividade agropecuária parece ser mais intenso, tendo em vista que o coeficiente aqui estimado é superior ao obtido na regressão de convergência absoluta (da Tabela 2).

Também se mostrou relevante para o incremento da produtividade o percentual de insumos utilizados por hectare, o percentual de tratores por hectare, assim como a área explorada. No caso desta última, o aumento da área explorada não necessariamente está atrelado a elevações da produtividade, pelo contrário, existe a tendência de diminuição da produtividade ao ampliar a área explorada, ceteris paribus.

Ao testar a hipótese de convergência condicional por meio do modelo de Durbin espacial (Tabela 3, modelo 4 e 5), o modelo mais apropriado foi o SDEM, segundo os critérios de informação Akaike e de Schwarz. Como corolário, a adição da defasagem espacial de todas as variáveis explicativas não alterou o sinal, e a significância do coeficiente que testa a convergência, indicando, assim, a existência de um processo de homogeneização da produtividade da terra na região.

Ao mesmo tempo, a dependência espacial que se manifesta no termo de erro não foi diferente de zero. Isto é, quando não se consegue modelar toda a fonte de dependência espacial oriunda do processo estocástico gerador de dados espaciais, 
Tabela 3. Resultado dos modelos de erro espacial (SEM), defasagem espacial (SAR), Durbin espacial do erro (SDEM) e Durbin espacial (SDM) para a convergência condicional

\begin{tabular}{|c|c|c|c|c|c|}
\hline \multirow{2}{*}{ Variável } & \multicolumn{5}{|c|}{ Modelo } \\
\hline & MQO (1) & SAR (2) & SEM (3) & SDM (4) & SDEM (5) \\
\hline Constante & $\begin{array}{c}6,050^{*} \\
(0,00)\end{array}$ & $\begin{array}{l}5,84^{*} \\
(0,00)\end{array}$ & $\begin{array}{c}6,237^{*} \\
(0,00)\end{array}$ & $\begin{array}{c}3.63^{* *} \\
(0,09)\end{array}$ & $\begin{array}{l}3,014 \\
(0,11)\end{array}$ \\
\hline Ln Area & $\begin{array}{c}-0,213^{* *} \\
(0,09)\end{array}$ & $\begin{array}{l}-0,135 \\
(0,28)\end{array}$ & $\begin{array}{c}-0,243^{*} \\
(0,05)\end{array}$ & $\begin{array}{l}-0,193 \\
(0,14)\end{array}$ & $\begin{array}{l}-0,113 \\
(-0,33)\end{array}$ \\
\hline Ln Assis. & $\begin{array}{c}0,0483 \\
(0,71)\end{array}$ & $\begin{array}{l}0,129 \\
(0,32)\end{array}$ & $\begin{array}{l}0,023 \\
(0,85)\end{array}$ & $\begin{array}{l}0,058 \\
(0,64)\end{array}$ & $\begin{array}{l}0,096 \\
(0,40)\end{array}$ \\
\hline Ln Gini & $\begin{array}{l}-0,329 \\
(0,21)\end{array}$ & $\begin{array}{l}-0,277 \\
(0,27)\end{array}$ & $\begin{array}{l}-0,333 \\
(0,18)\end{array}$ & $\begin{array}{l}-0,22 \\
(0,37)\end{array}$ & $\begin{array}{l}-0,226 \\
(0,36)\end{array}$ \\
\hline Ln Ins. & $\begin{array}{c}0,119^{* *} \\
(0,07)\end{array}$ & $\begin{array}{c}0,135^{*} \\
(0,03)\end{array}$ & $\begin{array}{l}0,124^{*} \\
(0,05)\end{array}$ & $\begin{array}{l}0,152^{*} \\
(0,02)\end{array}$ & $\begin{array}{c}0,171^{*} \\
(0,00)\end{array}$ \\
\hline Ln L & $\begin{array}{l}-0,091 \\
(0,65)\end{array}$ & $\begin{array}{l}0,064 \\
(0,76)\end{array}$ & $\begin{array}{l}-0,164 \\
(0,41)\end{array}$ & $\begin{array}{l}-0,122 \\
(0,54)\end{array}$ & $\begin{array}{l}-0,024 \\
(0,89)\end{array}$ \\
\hline Ln Maq. & $\begin{array}{l}-0,05 \\
(0,69)\end{array}$ & $\begin{array}{l}-0,128 \\
(0,31)\end{array}$ & $\begin{array}{l}-0,012 \\
(0,92)\end{array}$ & $\begin{array}{c}0,06 \\
(0,68)\end{array}$ & $\begin{array}{l}0,007 \\
(0,95)\end{array}$ \\
\hline Ln Pec. & $\begin{array}{l}-0,140 \\
(0,25)\end{array}$ & $\begin{array}{l}-0,139 \\
(0,22)\end{array}$ & $\begin{array}{l}-0,147 \\
(0,19)\end{array}$ & $\begin{array}{c}-0,193^{* *} \\
(0,07)\end{array}$ & $\begin{array}{c}-0,197^{* *} \\
(0,07)\end{array}$ \\
\hline Ln Trat. & $\begin{array}{c}0,223^{* *} \\
(0,07)\end{array}$ & $\begin{array}{c}0,217^{* *} \\
(0,06)\end{array}$ & $\begin{array}{c}0,216^{* *} \\
(0,08)\end{array}$ & $\begin{array}{l}0,080 \\
(0,61)\end{array}$ & $\begin{array}{c}0,06 \\
(0,64)\end{array}$ \\
\hline Ln PT95/96 & $\begin{array}{c}-0,893^{*} \\
(0,00)\end{array}$ & $\begin{array}{c}-0,868^{*} \\
(0,00)\end{array}$ & $\begin{array}{c}-0,925^{*} \\
(0,00)\end{array}$ & $\begin{array}{c}-1,025^{*} \\
(0,00)\end{array}$ & $\begin{array}{l}-1,02^{*} \\
(0,00)\end{array}$ \\
\hline Ln W Area & - & - & - & $\begin{array}{l}0,089 \\
(0,61)\end{array}$ & $\begin{array}{l}0,067 \\
(0,69)\end{array}$ \\
\hline Ln W Assis. & - & - & - & $\begin{array}{l}0,294 \\
(0,24)\end{array}$ & $\begin{array}{l}0,235 \\
(0,32)\end{array}$ \\
\hline Ln W Gini & - & - & - & $\begin{array}{l}0,010 \\
(0,98)\end{array}$ & $\begin{array}{l}-0,038 \\
(0,93)\end{array}$ \\
\hline Ln W Ins. & - & - & - & $\begin{array}{l}-0,130 \\
(0,08)\end{array}$ & $\begin{array}{c}0,144^{*} \\
(0,05)\end{array}$ \\
\hline Ln W L & - & - & - & $\begin{array}{l}0,434 \\
(0,13)\end{array}$ & $\begin{array}{l}0,384 \\
(0,17)\end{array}$ \\
\hline Ln W Maq. & - & - & - & $\begin{array}{l}-0,105 \\
(0,60)\end{array}$ & $\begin{array}{l}-0,098 \\
(0,59)\end{array}$ \\
\hline Ln W Pec. & - & - & - & $\begin{array}{c}0,335 \\
(0,188)\end{array}$ & $\begin{array}{c}0,30 \\
(0,21)\end{array}$ \\
\hline Ln W Trat. & - & - & - & $\begin{array}{l}-0,166 \\
(0,48)\end{array}$ & $\begin{array}{c}0,15 \\
(0,50)\end{array}$ \\
\hline Ln W PT95/96 & - & - & - & $\begin{array}{c}0,728^{*} \\
(0,00)\end{array}$ & $\begin{array}{c}0,775^{*} \\
(0,00)\end{array}$ \\
\hline$\lambda$ & - & - & $\begin{array}{l}0,207 \\
(0,16)\end{array}$ & - & $\begin{array}{l}-0,263 \\
(0,20)\end{array}$ \\
\hline$\rho$ & - & $\begin{array}{l}-0,518 \\
(0,07) \\
\end{array}$ & - & $\begin{array}{l}0,313 \\
(0,75) \\
\end{array}$ & - \\
\hline $\mathrm{R}^{2}$ ou pseudo $\mathrm{R}^{2}$ & 0,62 & 0,62 & 0,62 & 0,71 & 0,71 \\
\hline I Moran do resíduo & $1,95^{* *}$ & $0,17^{*}$ & 0,09 & $-0,08$ & $-0,08$ \\
\hline Crit. informaçãoAkaike & - & - & - & 203,7 & 201 \\
\hline Crit. Schwarz & - & - & - & 213,8 & 209 \\
\hline ML $\rho$ (defasagem) & 0,747 & - & - & - & - \\
\hline MLR $\rho$ (defasagem robusta) & $7,67 *$ & - & - & - & - \\
\hline ML $\lambda$ (erro) & 0,86 & - & - & - & - \\
\hline MLR $\lambda$ (erro robusto) & $7,78^{*}$ & - & - & - & - \\
\hline
\end{tabular}

Nota: Entre parênteses refere-se ao p-valor. * Significativo a um nível de significância de 5\%. PT95/96 refere-se à produtividade da terra de 1995/1996; Área é a área explorada (em ha); L é a mão de obra por hectare; Assis compõe o percentual de estabelecimento com assistência técnica regular; Maq. refere-se às máquinas e implementos agrícolas por hectare; Trat. são os tratores por hectares; Ins. refere-se ao custo com insumos (R $\$ /$ hectare); Pec. é o percentual da área explorada destinada à pecuária; Gini refere-se ao índice de concentração da terra; $\lambda$ é o parâmetro do erro autorregressivo espacial; $\rho$ é o coeficiente autorregressivo espacial; $W$ é um vetor $n x 1$ de defasagens espaciais; Ln é o logaritmo; ML refere-se ao multiplicador de lagrange.

Fonte: Resultado da pesquisa. 
a parte da dependência não modelada acaba se manifestando no padrão do erro aleatório entre as regiões vizinhas (representado pelo parâmetro $\lambda$ ), como ocorreu quando se testou a convergência absoluta (Tabela 2).

Porém, no modelo de convergência condicional, o parâmetro $\lambda$ perdeu significância, justamente porque o seu efeito passou a ser capturado pelas variáveis estruturais inclusas no modelo, bem como pelas suas defasagens espaciais. Esse é o caso do percentual da área explorada destinada à pecuária (efeito negativo), custo com insumos por hectare (relação positiva), defasagem do custo com insumos por hectare (positivo), e da própria defasagem da produtividade inicial, todas significativas em um nível de significância de $5 \%$.

No caso desta última, além de se constatar a existência de um processo de convergência, aquelas microrregiões que inicialmente estavam rodeadas por microrregiões com produtividade mais alta tenderam a ter taxas de crescimento da produtividade relativamente superiores, com um efeito de transbordamento da produtividade para as microrregiões circunvizinhas. Esse transbordamento pode advir das técnicas de produção que podem estar sendo difundidas entre os agricultores, insumos modernos, dentre outros elementos.

Em resumo, o fato de o coeficiente da produtividade da agropecuária inicial ser significativo e superior, em valor absoluto, na equação de convergência condicional, associado à relevância estatística e teórica das variáveis de controle, mostra a superioridade da hipótese de convergência condicional sobre a hipótese de convergência absoluta. Isso significa que, no longo prazo, as microrregiões do Sul, com características estruturais semelhantes, tendem a convergir para o mesmo nível de produtividade da agropecuária.

\section{Considerações finais}

A região Sul do Brasil, formada pelos estados do Paraná, de Santa Catarina e do Rio Grande do Sul, detém uma participação elevada no valor agregado do setor agropecuário e uma das mais altas produtividades do país. Desse modo, a elevação da produtividade da agropecuária implica diretamente a competitividade do setor, aprimorando, com isso, a produção de alimentos, a sua capacidade de inserção internacional bem como, na geração de trabalho e renda no campo.

Diante da importância do setor agropecuário para o Brasil e para a região Sul, o objetivo do presente estudo foi o de analisar a produtividade da agropecuária na região Sul do Brasil, testando as hipóteses de convergência absoluta e condicional da referida variável. Nesse caso, como a unidade de análise foram as microrregiões, estimou-se o modelo de convergência por meio das técnicas da econometria espacial.

Por meio de uma Análise Exploratória dos Dados Espaciais (AEDE), confirmou-se a hipótese de que a distribuição espacial da produtividade da terra não é aleatória, pelo contrário, existe uma correlação positiva nos dados. Isso significa que as microrregiões com elevada (baixa) produtividade são rodeadas por microrregiões com alta (baixa) produtividade. E, mediante a análise do mapa de clusters LISA, evidenciaram-se alguns agrupamentos locais (clusters), localizados, sobretudo, no Rio Grande do Sul.

Findada essa análise preliminar, partiu-se, então, para a estimação do modelo de convergência absoluta e condicional. No caso da convergência absoluta, constatou-se um processo de convergência da produtividade da terra, sendo esse resultado robusto, pois é independente do modelo espacial estimado. Ademais, além do processo de convergência, constatou-se a existência de um processo de dependência espacial entre as microrregióes, evidenciando que o crescimento da produtividade de uma determinada região afeta, positivamente, o crescimento da produtividade das microrregióes circunvizinhas.

Ademais, no caso da convergência condicional, a hipótese também foi confirmada. Nesse modelo, o coeficiente da produtividade da agropecuária inicial foi significativo e se mostrou superior, em valor absoluto, ao obtido no modelo de convergência absoluta. Isso porque algumas variáveis estruturais inseridas no modelo, bem 
como as suas defasagens espaciais, se mostraram importantes na explicação da convergência da produtividade. Isso revela que, no longo prazo, as microrregiões com características estruturais semelhantes tendem a convergir para o mesmo nível de produtividade da agropecuária.

O fato de se ter obtido em todos os testes a presença de convergência absoluta e condicional indica um cenário positivo para a agropecuária da região Sul, o que permite vislumbrar eficiências produtivas cada vez maiores, especialmente se as ações forem dirigidas ao setor numa visão regional. A evidência de uma dependência espacial entre as microrregióes implica que os ganhos em termos de políticas não são restritos a uma determinada microrregião, mas, sim, são transbordados para as regiões vizinhas.

$\mathrm{O}$ processo de convergência existe. No entanto, não são apenas as características iniciais que fomentam essa convergência, mas, sim, os elementos estruturais, como a introdução de novas tecnologias (no caso específico deste trabalho, os insumos). Nesse sentido, naquelas áreas menos produtivas (talvez devido à arenização), como no extremo do Rio Grande do Sul, as ações públicas devem alterar as características estruturais, para que o processo de convergência seja ainda mais intenso, beneficiando toda região.

Cabe destacar que uma das limitações deste estudo se refere ao uso de um único deflator para todas as microrregiões sulinas. O ideal seria um deflator específico para cada região, reconhecendo, assim, as especificidades de composição do valor adicionado de acordo com as diferentes culturas produzidas em cada microrregião. Porém, tal feito por si só já seria um novo trabalho dada a sua complexidade e a disponibilidade de dados. Portanto, trabalhos futuros podem enriquecer os resultados aqui encontrados se utilizarem deflatores específicos de cada região.

\section{Referências}

AGROANALYSIS. Produtividade na agricultura brasileira. Revista de Agronegócio da FGV. 2008.
Disponível em: < http://www.agroanalysis.com.br> Acesso em: 05 mar 2015.

ALMEIDA, E. Econometria espacial aplicada. Campinas: Alinea, 2012. 498 p.

. e HADDAD, E. A. MEECA: um Modelo Econométrico Espacial para Projeção Consistente de Culturas Agropecuárias. RER, Rio de Janeiro, v. 42, n. 3 , p. 507-527, jul/set 2004.

., PEROBELli, F. S. e FERREIRA, P. G. C. Existe convergência espacial da produtividade agrícola no Brasil? Revista de Economia e Sociologia Rural, v. 46, n. 01, p. 31-52, jan./mar. 2008.

ALMEIDA, M. A. e GUANZIROLI, C. E. Análise exploratória espacial e convergência condicional das taxas de crimes em Minas Gerais nos anos 2000. In: Encontro Nacional de Economia (ANPEC), XLI, Anais..., 2013, Foz do Iguaçu (PR), Anais, 2013.

ALVES, E. O que significam as medidas de produtividade da agricultura? Revista de Economia e Agronegócio, v. 8, n. 3, p. 349-370, set./dez. 2010.

ALVIN, C. e DIMONDE, C. Indicadores de Produtividade de Capital na Agropecuária Brasileira. Economia E Energia, n. 77, abr./jun. 2010.

AMORIM, A. L., CORONEL, D. A. e TEIXEIRA, E. C.. A Agropecuária na Economia Brasileira: uma análise de Insumo Produto. Anais..., XLVII Congresso da Sociedade Brasileira de Economia, Administração e Sociologia, Porto Alegre-RS-Brasil, p. 01-15, 2009.

BACHA, C. J. C. Economia e política agrícola no Brasil. São Paulo: Atlas, 2004.

. The evolution of Brazilian agriculture from 1987 to 2009. In: BAER, W. e FLEISCHER, D. The economics of Argentina and Brazil: a comparative perspective. Northampton, Mass: Edward Elgar Publishing, 2011, p. 97-129.

BARRETO, R. C. S. e ALMEIDA, E. S. A contribuição do capital humano para o crescimento econômico e convergência espacial do PIB per capita no Ceará. Ceará: IPECE, 2008.

. e ALMEIDA, E. S. A contribuição da pesquisa para convergência e crescimento da renda agropecuária no Brasil. RESR, Piracicaba, SP, v. 47, n. 3, p. 719-737, jul./set. 2009.

., ALMEIDA, E. S. e LIMA, J. E. Convergência espacial do PIB per capita no estado do Ceará. Revista de Economia, Curitiba, v. 36, p. 25-40, 2010.

BARRO, R. e SALA-I-MARTIN, X. Economic growth. New York: MacGrawHill, 1995. 
BRUGNARO, R. e BACHA, C. J. C. Análise da Participação da agropecuária no PIB do Brasil de 1986 a 2004. Estud. Econ., São Paulo, v. 39, n. 1, mar. 2009. Disponível em: <http://dx.doi.org/10.1590/S010141612009000100005>. Acesso em: 3 mar. 2015.

COSTA, L. V. et al. Produtividade agrícola e segurança alimentar dos domicílios das regiões metropolitanas brasileiras. Rev. Econ. Sociol. Rural, Brasília, v. 51, n. 4, dez. 2013.

FELEMA, J., RAIHER, A. P. e FERREIRA, C. R. Agropecuária Brasileira: desempenho regional e determinantes de produtividade. RESR, Piracicaba-SP, v. 51, n. 3, p. 555-574, jul./set. 2013.

FIGUEIREDO, M. G. Agricultura e estrutura produtiva do Estado do Mato Grosso: uma análise insumo-produto. 2003. Dissertação (Mestrado em Economia) - Programa de Pós-graduação em Economia, Escola Superior de Agricultura "Luiz de Queiroz", Universidade de São Paulo, Piracicaba, 2003.

FLORAX, R. J. G. M., FOLMER, H. e REY, S. J. Specification searches in spatial econometrics: The relevance of Hendry's methodology. Regional Science and Urban Economics, v. 33, n. 5, p. 557-79, 2003.

FOCHEZATTO, A. e STÜLP, V. J. Análise da convergência da produtividade da mão-de-obra agropecuária entre os estados brasileiros: aplicação de matrizes de Markov, 1990-2000. RESR, Piracicaba, SP, v. 46, n. 03, p. 739-765, jul./set. 2008.

GASQUES, J. G. et al. Condicionantes da produtividade da agropecuária brasileira. Brasília: IPEA, 2004. 31 p. (Texto para discussão, 1017).

GASQUES, J. G. et al. Produtividade da Agricultura Brasileira e os Efeitos de Algumas Políticas. Revista de Política Agrícola, v. n.3, p. 83, 2012.

GUERREIRO, E. Produtividade do trabalho e da terra na agropecuária paranaense, 1995. 136 f. Dissertação (Mestrado em Agronomia) - Departamento de Economia, Escola Superior de Agricultura Luiz de Queiroz, Universidade de São Paulo, Piracicaba.

HOFFMANN, R. e JAMAS, A. L. A produtividade da terra e do trabalho na agricultura de 332 microrregiões do Brasil. In: Congresso Brasileiro de Economia e Sociologia Rural (SOBER), 28, Florianópolis, 1990. Anais... Brasília: SOBER, 1990, v. 2, p. 21-40.

HWA, E-C. The contribution of agriculture to economic growth: some empirical evidence. World Development, v. 16, n. 11, p. 1329-1339, 1988.

KELEJIAN, H. H. e PRUCHA, I. R. Specification and estimation of spatial autoregressive models with autoregressive and heteroskedastic disturbances. Journal of Econometrics, n. 157, p. 53-67, 2010.

LEWIS, A. O desenvolvimento econômico com oferta ilimitada de mão-de-obra. In: AGARWALA, A. N. e SINGH, S. P. (Coords.). A economia do subdesenvolvimento. Rio de Janeiro: Cia Editora Forense, 1969.

LI, G., ZENG, X. e ZHANG L. Study of agricultural productivity and its convergence across China's regions. Review of Regional Studies, v. 38, p. 361-379, 2008.

LIMA, J. R. et al. O uso das terras no sul do Brasil: uma análise a partir de indicadores de localização. RER, Rio de Janeiro, v. 44, n. 04, p. 677-694, out./dez. 2006.

LOPES, J. L. Avaliação do processo de convergência da produtividade da terra na agricultura brasileira no período de 1960 a 2001. Tese de Doutorado, ESALQ/USP, 2004.

MARTIM, R. e SUNLEY, P. Convergência lenta? Anova teoria do crescimento endógeno e o desenvolvimento regional. Cadernos IPPUR/UFRJ, Rio de Janeiro, v. 14, n. 1, ano 0, p. 7-12, jan.jul. 2000.

MORAN, P. A. P. The interpretation of statistical maps. Journal of Royal Statistical Society, v. 10, n. 2, p. 243-251, 1948.

OLIVEIRA JUNIOR, J. N. et al. Determinação dos Clubes de Convergência da Renda per capita Agrícola - Uma Análise para os Municípios Cearenses. Revista de Economia e Sociologia Rural, v. 47, p. 995-1022, 2009.

OZAKi, V. Análise espacial da produtividade agrícola no estado do Paraná: implicações para o seguro agrícola. RESR, Piracicaba, SP, v. 46, n. 03, p. 869-886, jul./set. 2008.

PENNA, C. e LINHARES, F. Uma Nota Sobre "Teste da Convergência do PIB per capita da Agropecuária no Brasil". RESR, Piracicaba-SP, v. 51, n. 1, p. 091-104, jan./ mar. 2013.

. e LINHARES, F. Uma nota sobre "Teste da convergência do PIB per capita da agropecuária no Brasil". Rev. Econ. Sociol. Rural, Brasília, v. 51, n. 1, mar. 2013.

PHILLIPS, P. C. B. e SUL, D. Transition modeling and econometric convergence tests. Econometrica, Econometric Society, v. 75, n. 6, p. 1771-1855, nov. 2007.

POUDEL, B. N., PAUDEL, K. e ZILBERMAN, D. Agricultural productivity convergence: myth or reality. Journal of Agricultural and Applied Economics, v. 43, p. 143-156, 2011.

REY, J. S. e MONTOURI, B. D. US Regional income convergence: a spatial econometric perspective. Regional Studies, v. 33, n. 2, p. 143- 156, 1999. 
RODRIGUES, J. A. O papel da agricultura no processo de desenvolvimento econômico e as políticas governamentais para o setor agrícola. Revista de Administração Pública, Rio de Janeiro, p. 09-37, 1978.

ROSTOW, W. W. Etapas do desenvolvimento econômico: um manifesto não comunista. 6. ed. Rio de Janeiro: Zahar Editores, 1978.

SANTOS, M. J. e GUERREIRO, E. Produtividade do trabalho e da terra na agropecuária paranaense. Publ. UEPG Ci. Hum., Ci. Soc. Apl., Ling., Letras e Artes, Ponta Grossa, v. 13, n. 2, p. 59-78, dez. 2005.

SILVA, G. L. S. P., VICENTE, J. R. e CASER, D. V. Mudança Tecnológica e Produtividade do Milho e da
Soja No Brasil. Revista Brasileira de Economia, Rio de Janeiro, v. 47, n. 2, p. 281-303, 1993.

SOUZA, N. J. e PÔRTO JR., S. S. Crescimento regional e novos testes de convergência para os municípios da região nordeste do Brasil. 2002. URL: Disponível em: <www. ufrgs.br/ppge/pcientifica/2002_11.pdf>. Acesso: jan. 2015.

SUERTGARAY, D. M. A. Erosão nos campos sulinos: arenização no sudoeste do Rio Grande do Sul. Revista Brasileira de Geomorfologia, v. 12, n. 3, p. 61-74, 2011.

VICENTE, J. R. Produtividade total de fatores e eficiência no setor de lavouras da agricultura brasileira. Revista de Economia e Agronegócio, v. 9, p. 303-324, 2011. 